\title{
Structural Analysis of Rear Pressure Bulkhead of Typical Transport Aircraft
}

\author{
Ashish Rawat, Suraj Sharma, Amir Shaikh, Nithin Kumar K. C., Shwetank Avikal
}

\begin{abstract}
In this study, many researchers studied flat bulkhead, but Dome-shaped bulkhead is more preferable as it withstands pressure loads. We modeled a rear pressure bulkhead of a typical transport aircraft using CATIA V5 modeling software. Finite element analyses were carried out by the rear pressure bulkhead subjected to the boundary conditions (Fuselage is fixed and attached to the aircraft honeycomb structure and 0.1Mpa pressure is applied to the bulkhead). From the FEA of the rear pressure bulkhead, we obtained Von-Misses stresses and the deformations were obtained. The maximum displacement of $5.46 \mathrm{~mm}$ was observed on the dome. The maximum normal stress at the circumferential direction was about 306Mpa.
\end{abstract}

Keywords: Transport Aircraft, Pressure Bulkhead, Stress analysis, Fuselage, composites

\section{INTRODUCTION}

Aircraft are mostly used for transportation of goods and public. An aircraft structure is made up of four basic sections namely fuselage, wings, horizontal stabilizers and empennage and structural materials, and frame design [1]. A fuselage is the long tubular structure which is the main part of the aircraft where all the passengers are kept and the luggage compartment is accommodated. The fuselage is the single unit but divided into different segments as the cockpit, luggage room, and passenger area [2].

A fuselage is the main body section, tubular in design which holds crew, passengers, and cargo and holds all the pieces of an aircraft together as a frame. A fuselage can be of different types according to the requirement or purpose. The fuselage structure is the assembly of the main body and front and rear bulkhead [4].

A bulkhead is a part of the fuselage structure riveted at the front end and rear end. The rear end bulkhead is a thin sheet dome or hemispherical shaped component structured and supported with stiffeners for better sustainability against the perpendicular pressure load. As the thin dome shape only cannot withstand high pressures, stiffeners are welded across the sheet to give it the rigidity against the perpendicular pressure load [5].

The atmospheric pressure of $760 \mathrm{~mm} \mathrm{Hg}$ is human comfort pressure.

Revised Manuscript Received on April 25, 2019.

Ashish Rawat, Department of Mechanical Engineering, Graphic Era Deemed to be University, Dehradun, India.

Suraj Sharma, Department of Mechanical Engineering, Graphic Era Deemed to be University, Dehradun, India.

Amir Shaikh, Department of Mechanical Engineering, Graphic Era Deemed to be University, Dehradun, India.

Nithin Kumar K.C., Department of Mechanical Engineering, Graphic Era Deemed to be University, Dehradun, India. E-mail kcnkumar@ymail.com

Shwetank Avikal, Department of Mechanical Engineering, Graphic Era Hill University, Dehradun, India.
On increasing the altitude, the atmospheric pressure decreases. So constant pressure is maintained inside the fuselage for human comfort. For this, the fuselage must be airtight [6]. Also at high altitude, the pressure difference in the fuselage and the surrounding is so high that the aircraft structure should be strong enough to withstand this. But considering the aviation and the fuel economy, the aircraft should be light. So an optimized structure is made which is lighter and strong enough to bear the high pressure at that altitude [7]. The air inside the fuselage is circulated inside it only and not with the outside. Thus circulated air exerts the pressure on the rear bulkhead the most [8-9]. In this study, we are analyzing the pressure bulkhead to understand its behavior for the given boundary conditions. 


\section{MATERIALS AND METHOD}

The Fig.1. Shows the methodology followed in this study

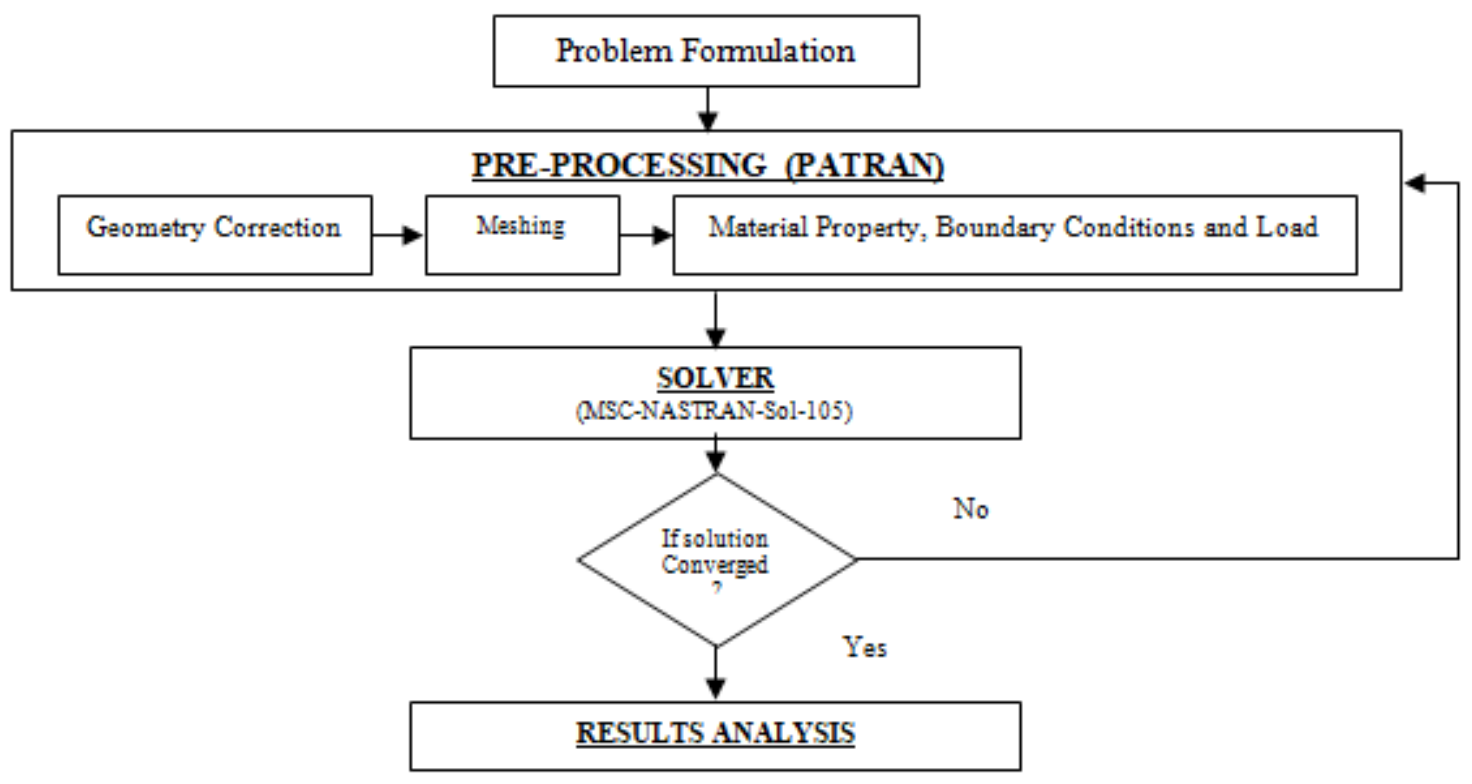

Fig. 1 Methodology

\subsection{Materials Properties}

The UD carbon prepreg material was used in the fabrication of Pressure bulkhead. The basic material properties used in this analysis are shown in Table 1 . The stacking sequence is [45/-45/0/90] s and Laminate thickness is $3 \mathrm{~mm}[10]$.

Table 1: Material properties of UD Carbon Fiber Composite

\begin{tabular}{ccccc}
\hline $\mathrm{E}_{11}(\mathrm{GPa})$ & $\mathrm{E}_{22}(\mathrm{GPa})$ & $\begin{array}{c}\mathrm{G}_{12} \\
(\mathrm{GPa})\end{array}$ & $\gamma_{12}$ & $\begin{array}{c}\rho \\
(\mathrm{g} / \mathrm{cm} 3)\end{array}$ \\
\hline 130 & 10 & 3 & 0.33 & 2.78 \\
\hline
\end{tabular}

Aluminum alloys are widely used in aerospace, automobile industries because of their low weight and high strength. These alloys are correction resistance and easy to fabricate. The Al-2024-T3 alloys are widely used in aerospace. In this study, Al 2024-T3 is considered for Fuselage and stiffeners in the analysis and its material properties are young's modulus $72 \mathrm{GPa}$, Poisson's ratio is 0.33 and density is $2.78 \mathrm{~g} / \mathrm{cm}^{3}$ [11-12].

\subsection{Boundary Conditions}

The analysis is of the rear pressure bulkhead for multiple loads where the pressure is crucial for the bulkhead. Therefore the result discussed in this paper details the pressure cause on it. Here the analysis of pressure load on the bulkhead is by applying ultimate pressure of $0.1 \mathrm{MPa}(14$ psi) normal to the inner surface of rear pressure bulkhead using PLOAD4 option of NASTRAN. All the linear DOF at nodes are constrained to forward end in the analysis of the fuselage skin [3].

\subsection{Three-dimensional modeling and Meshing}

The pre-processing and the post-processing of the finite element model were executed using MSC-Patran and solved in MSC/NASTRAN. The members like bulkhead contour and fuselage skin were modeled using the CATIA P3 V56R2016 (Fig.2) and the structural members like stringers were meshed using the CQUAD4 and CTRIA3 with PSHELL property in MSC-Nastran. Here all the composite parts were treated as 2D orthographic layered shell structural elements. These were modeled with the PCOMP property in MSC-Nastran [3]. The meshed model of the rear bulkhead with fuselage skin is shown in Fig. 3.

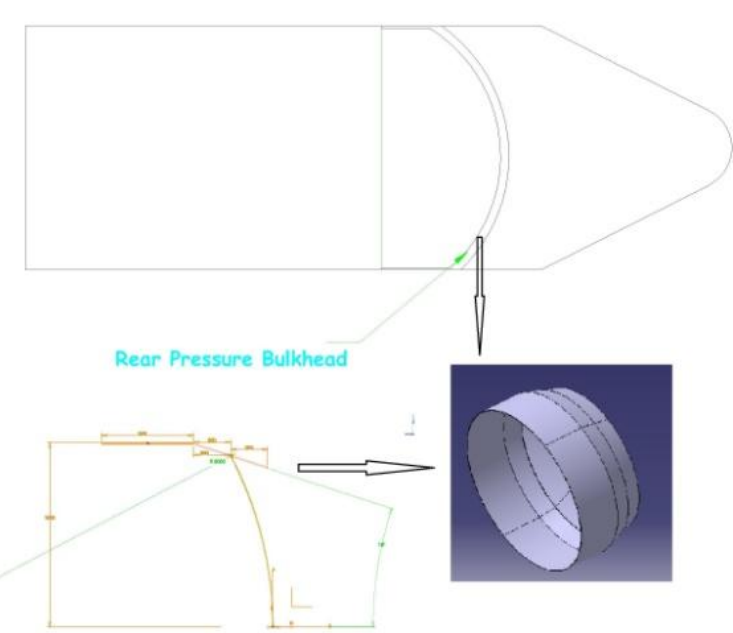

Fig.2 Cad Model 


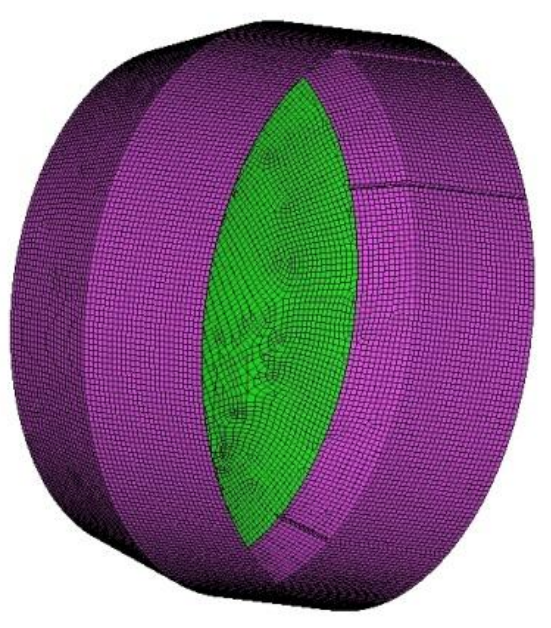

Fig.3 Meshed Model

\section{RESULTS AND DISCUSSIONS}

The rear pressure bulkhead is subjected to the boundary conditions (Fuselage is fixed and $0.1 \mathrm{Mpa}$ pressure is applied to the bulkhead). From the finite element analysis of the rear pressure bulkhead, the Von-Misses stresses and the deformations were obtained. The displacement contours are shown in Fig. 4 and 5. The maximum displacement was observed on the dome with $5.46 \mathrm{~mm}$. The maximum normal stress at the circumferential direction was nearly about 306Mpa.
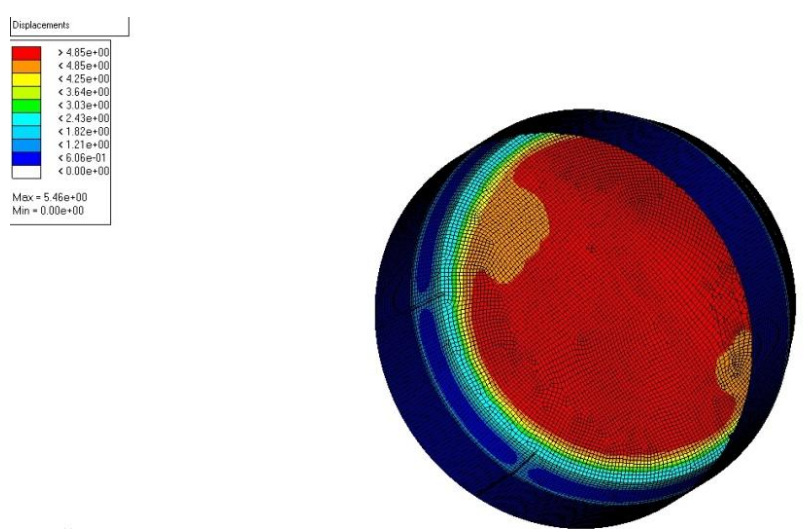

Fig. 4Displacement

The deformation is more in the center of the pressure bulkhead as compared to the circumferential direction. The Minimum $0.6 \mathrm{~mm}$ and maximum of $5.46 \mathrm{~mm}$ deformation are observed (Fig. 4).
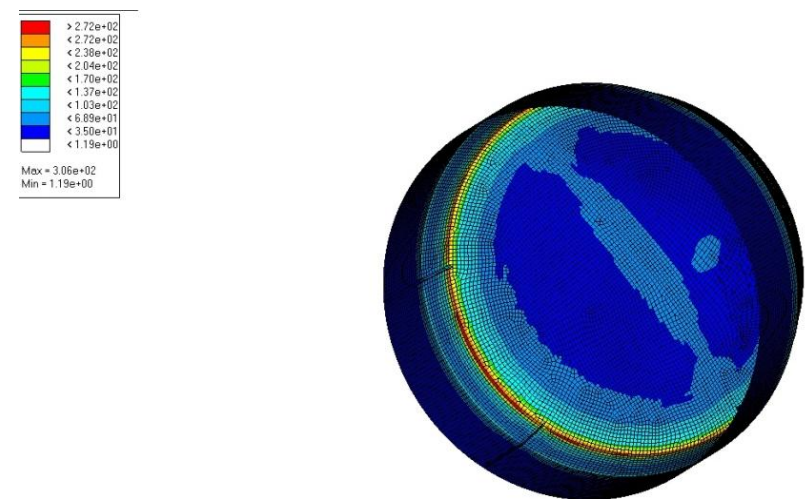

Fig. 5Maximum normal stresses
The stress distribution is more in the circumferential direction of the pressure bulkhead as compared to the center. The Minimum 1.19Mpa and maximum of 306Mpa stress are observed (Fig. 5).

\section{CONCLUSIONS AND FUTURE WORK}

The static stress analysis of rear pressure bulkhead was carried out meeting all the boundary conditions. The following conclusions were made.

$>$ The unstiffened pressure bulkhead will not withstand the given pressure load unless the bulkhead is stiffened.

> Many researchers studied flat bulkhead, but Domeshaped bulkhead is more preferable as it withstands pressure loads.

$>$ The maximum displacement of 5.46mmwas observed on the dome. The maximum normal stress at the circumferential direction was nearly about 306Mpa. This study gives the importance of usage of stiffeners because as the thickness increases the weight of the bulkhead increases.

The same work will be carried out by performing weight optimization using Yamada-Sun failure criteria for strength and buckling effect will be studied along with this.

\section{REFERENCES}

1. J.H. Kwon, et. al., A study on the fatigue crack growth behavior for the fuselage pressure bulkhead. Aerospace Techniques and Shipbuilding, Korus'99

2. J.C.Velosa, et.al., Development of a new generation of filament wound composite pressure cylinders. Composites Science and Technology, 69 (2009) Pp 1348-1353.

3. S. Venkatesh, et.al., Development And Certification Of Composite Rear Pressure Bulkhead For A Light Transport Aircraft,18th International Conference On Composite Materials, August 2011, Pp $1-6$.

4. M.R. Khalili, et. al., A new approach to static and dynamic analysis of composite plates with different boundary conditions, Composite Structures Vol. 69 (2005), Pp149-155

5. P. Linde, et. al., Modelling of inter-rivet buckling of hybrid composites, Composite Structures Vol. 72 (2006), Pp 221-228

6. M.C. Simmons, et. al., Pulse pressure loading of aircraft structural panels, Thin-Walled Structures Vol. 44 (2006), Pp496-506

7. W. Becker, et. al., comparison between test and analysis of a tank bulkhead loaded in the plastic, Aerospace Science and Technology Vol. 1 (1997) Pp77-81

8. R. Jones, et. al., On the analysis of composite structures with material and geometric nonlinearities, Composite Structures Vol. 50 (2000), Pp 417-431

9. T.C. Kennedy, et. al., Predicting failure of composite structures containing crack, Composites Part A Vol. 33 (2002), 583-588

10. J. Bayandor, et. al., Parametric optimization of composite shell structures for an aircraft Krueger flap, Composite Structures Vol. 57 (2002), Pp 415-423

11. Nithin Kumar K C, et. al., "Structural optimization of Composite stiffened panel of a Transport Aircraft Wing using CAE tools", Vol. 2, 4-5, 2015, Pp 2588-2594

12. http://asm.matweb.com/search/SpecificMaterial.asp?bassnum=MA20 24T3 ( Accessed on 19/1/2020)

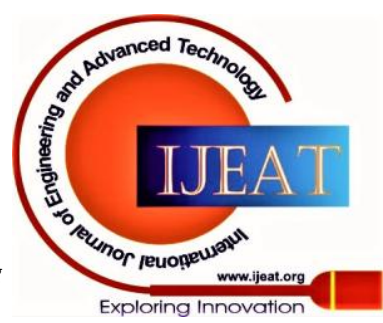

